\title{
Cinton sketches out his 'ethical guideposts' for modern biology
}

[WASHINGTON] In the most prominent speech of his presidency on research-related issues, President Bill Clinton called last Sunday (18 May) for Americans to remember that "science is not God", adding: "Our deepest truths remain outside the realm of science."

In a speech that has been noticed mainly for its call for development of an AIDS vaccine, Clinton also spoke widely on scientific ethics. He urged Congress to pass legislation banning genetic discrimination by health insurers. Referring to the recent cloning of a sheep, he said that "we should resist the temptation to replicate ourselves".

"Science has no soul of its own," said Clinton. "It is up to us to determine whether it will be used as a force for good or evil."

Clinton's call for an AIDS vaccine was accompanied by an announcement that a new centre devoted to AIDS vaccine research will be established at the National Institutes of Health (NIH). But as he did not increase the $\$ 148$ million AIDS vaccine budget at $\mathrm{NIH}$, the announcement has been met with some scepticism.

One highly placed AIDS scientist dismissed it as "pure politics". But others, such as Anthony Fauci, director of the National Institute of Allergy and Infectious Diseases (NIAID), welcomed the centre and called the ten-year goal an appropriate symbolic pledge. Harold Varmus, director of NIH, described the goal as "realistic".

In his speech, delivered as a commencement address at Morgan State University in Baltimore, Maryland, Clinton outlined four ethical "guideposts" for the coming "century of biology". These were: that science should be used to produce a better life for all, and not the few; that advances should not be used to discriminate and, to this end, that Congress should ban genetic discrimination by health insurers; that new technologies should not be allowed to compromise individual privacy, including medical records privacy; and that American science should "never [confuse] faith in technology with faith in God".

Referring to the government's Tuskegee Syphilis Study, in which 399 black men were left untreated, and to Cold War radiation experiments on US citizens, Clinton vowed that America would "not go back to those awful days in modern disguise".

Clinton dismissed some scientists' questions about whether the formidable obstacles can ever be overcome to produce an AIDS vaccine. "It is no longer a question of whether we can develop an AIDS vaccine, it is simply a question of when." He added that he would appeal to other countries to join

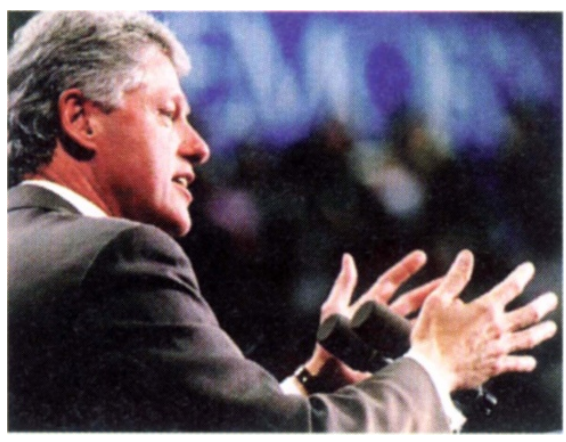

Clinton: getting to grips with AIDS research?

the US effort next month in Denver, at a summit of leading industrialized nations.

His pledge has been warmly welcomed by organizations addressing the global AIDS epidemic, which fear that the availability of protease inhibitors to treat AIDS patients in wealthy countries may undermine support for vaccine research (see Nature 382, 101; 1996). "This is the best news that the developing countries could have," says Jose Esparza, a vaccine adviser at the United Nations Programme on AIDS in Geneva, Switzerland.

Clinton also vowed to "challenge" the pharmaceutical industry to invest more money in AIDS vaccine development. This provoked a response from the president of the Pharmaceutical Research and Manufacturers of America that "HIV vaccine development depends more on scientists' tenacity and brilliance in the laboratories, not on politician's words".

But William Paul, director of the NIH's Office of AIDS Research, says that drug com- pany executives have "assured" NIH that "if we can show the way [with the science] they are prepared to follow through" with vaccine development.

Several AIDS groups were supportive of Clinton's call. Gary Rose of the Washingtonbased AIDS Action Council calls it a "hopeful" step. "We agree with the president that [vaccine development] should be one of the major targets now," says Arthur Ammann, president of the American Foundation for AIDS Research. "We've got to look at where the epidemic is going."

But others argue that Clinton was fed meaningless declarations by his Advisory Council on HIV/AIDS, which proposed the ten-year goal in April. "These are people who don't deal with the scientific issues. They believe that the wish is the father of the deed," says a prominent AIDS researcher, maintaining that, without more money, the declaration is purely cosmetic.

According to Varmus, despite the lack of new money accompanying Clinton's announcement, "there are ways" to make adequate resources available for the centre. Fauci says the president's declaration will give the NIH leverage in coming years to land healthy AIDS vaccine research budgets even as other government programmes shrink.

The NIH vaccine research centre will consolidate AIDS vaccine research now located at the NIAID and the National Cancer Institute. Varmus hopes to house 50 to 100 core scientists and staff in one facility within one to two years, and involve other $\mathrm{NIH}$ scientists in a larger, 'virtual' centre without walls.

MeredithWadman

\section{Bioethics commission gets extended term}

[WASHINGTON] Prompted largely by public concern about humans used in

experiments, President Bill

Clinton last week extended

by two years the life of the

national bioethics

commission, which is to report to him on cloning at the end of this month (see Nature 387, 217; 1997).

"The need for this commission is clear," Clinton said at a ceremony at the White House during which he announced that he was using an executive order to extend the life of the National
Bioethics Advisory Commission until October 1999. The commission would otherwise have ceased work in October this year.

The brief mandate and thin resources of the 18member commission had come under fire from Republicans at a congressional hearing two weeks ago. There, and in news reports since, the US system for the protection of human subjects has been portrayed as inadequate.

"We must be able to call on the thoughtful, collective wisdom of experts and community representatives to find ways to further strengthen our protection for subjects in human research," Clinton said. Part of the commission's mandate is to focus on the welfare of human research subjects.

The chairman of the commission, Harold Shapiro, who is president of Princeton University, said of Clinton's announcement: "The president has assured me all along that this was going to happen. It's nice to get it done."

M.w. 